\title{
Investigation of $\mathrm{HNO} 2$ Production in Solvent Extraction Organic Phases
}

\author{
Leigh R. Martin
}

September 2014

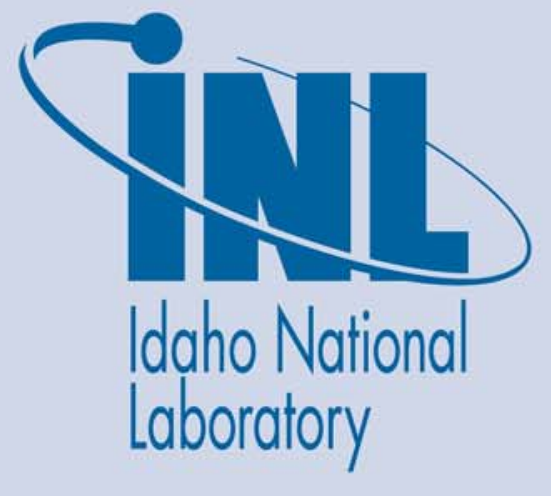

The INL is a U.S. Department of Energy National Laboratory operated by Battelle Energy Alliance 


\title{
Investigation of $\mathrm{HNO} 2$ Production in Solvent Extraction Organic Phases
}

\author{
Leigh R. Martin
}

September 2014

\author{
Idaho National Laboratory \\ Idaho Falls, Idaho 83415
}

http://www.inl.gov

Prepared for the

U.S. Department of Energy

Office of Nuclear Energy

Under DOE Idaho Operations Office

Contract DE-AC07-05ID14517 


\section{Investigation of $\mathrm{HNO}_{2}$ Production in Solvent Extraction Organic Phases}

Fuel Cycle Research \& Development

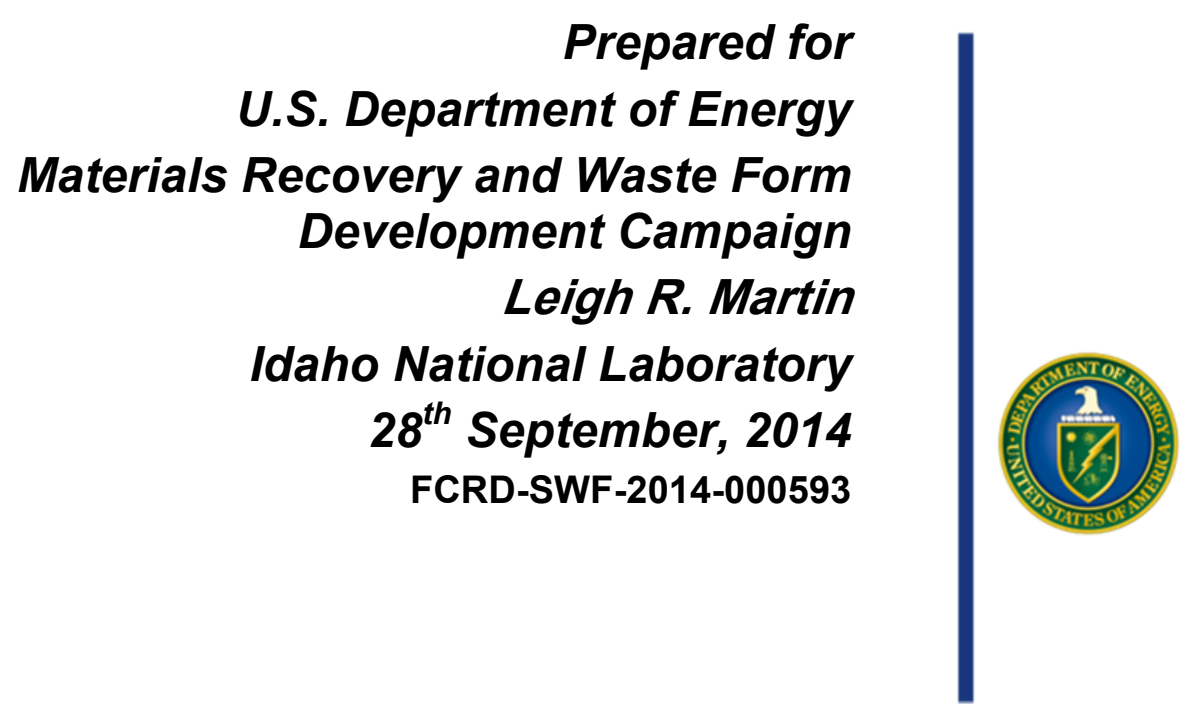




\section{DISCLAIMER}

This information was prepared as an account of work sponsored by an agency of the U.S. Government. Neither the U.S. Government nor any agency thereof, nor any of their employees, makes any warranty,

expressed or implied, or assumes any legal liability or responsibility for the accuracy, completeness, or usefulness, of any information, apparatus, product, or process disclosed, or represents that its use would not infringe privately owned rights. References herein to any specific commercial product, process, or service by trade name, trade mark, manufacturer, or otherwise, does not necessarily constitute or imply its endorsement, recommendation, or favoring by the U.S. Government or any agency thereof. The views and opinions of authors expressed herein do not necessarily state or reflect those of the U.S. Government or any agency thereof. 
Investigation of $\mathrm{HNO}_{2}$ Production in Solvent Extraction Organic Phases

$28^{\text {th }}$ September, 2014 


\section{SUMMARY}

This document is a letter report that was prepared to meet FCR\&D level 4 milestone M4FT14IN0304054, "Investigate $\mathrm{HNO}_{2}$ production in solvent extraction organic phases." This work was carried out under the auspices of the Fundamental Radiation Chemistry FCR\&D work package. This document reports on an initial tests performed to follow $\mathrm{HNO}_{2}$ formation in reference flowsheet relevant organic phases. 


\section{CONTENTS}

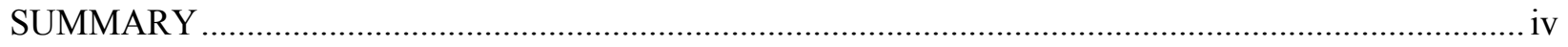

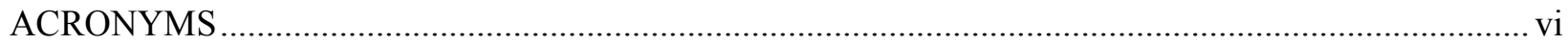

\section{FIGURES}

No table of figures entries found.

\section{TABLES}

No table of figures entries found. 
ACRONYMS

FCR\&D Fuel Cycle Research and Development

INL Idaho National Laboratory

US DOE United States Department of Energy

UV-Vis Ultraviolet-visible 



\section{MATERIALS RECOVERY AND WASTE FORM DEVELOPMENT CAMPAIGN}

\section{Introduction}

As the US develops advanced separation methods for the processing of used nuclear fuel, the option for co-extraction of uranium, neptunium and plutonium is becoming increasingly attractive for the first cycle process. However, neptunium has a rich redox chemistry and offers two oxidation states that can be extracted in such a process, but a third that is inextractable. The $\mathrm{Np}(\mathrm{IV})$ and $\mathrm{Np}(\mathrm{VI})$ ions can both be extracted by $30 \%$ TBP in an organic diluent for used nuclear fuel processing purposes. Recent research has highlighted that in aqueous solution where $\mathrm{Np}, \mathrm{HNO}_{3}, \mathrm{HNO}_{2}$ are present redox control of the $\mathrm{Np}$ ions becomes difficult. ${ }^{1-3}$ This becomes further complicated in irradiated solutions of $\mathrm{Np}$. Although these reactions have been explored in the aqueous phase there is as yet very little information on these species in the organic phase. This letter report details the researchers' initial findings of the production of $\mathrm{HNO}_{2}$ in irradiated TBP in a normal alkane diluent solutions and the related effects on neptunium speciation.

\section{Experimental}

Solutions of $\mathrm{Np}(\mathrm{VI})$ were generated electrochemically in $0.1 \mathrm{M} \mathrm{HNO}_{3}$ then aqueous phase acidity adjusted to either $0.1,1,2,4,6$ or $8 \mathrm{M}$ by the addition of appropriate concentrations of nitric acid. Traditional solvent extraction experiments were then performed to extract $\mathrm{Np}(\mathrm{VI})$ into TBP organic phase. The organic phase was then loaded into a 1-cm UV-vis cuvette. Steady-state $\gamma$-radiolysis was performed on the cuvettes containing either the organic phase only and organic/ aqueous phase in contact with each other. A Cary 6000i UV-vis spectrophotometer was used to measure absorbance changes the organic phase after irradiation to monitor oxidation state changes.

\section{Results}

Initial experiments were run at all acidities and varying gamma dose, in the absence of $\mathrm{Np}$, to identify if $\mathrm{HNO}_{2}$ would be produced from the extracted $\mathrm{HNO}_{3}$ present in the organic phase. Figure 1 shows the results of this study for $1.0 \mathrm{M} \mathrm{HNO}_{3}$. This change in the absorbance spectrum indicates a build-up of $\mathrm{HNO}_{2}$ as the total dose increased. Further, it appears that there is a second species that forms that is as yet unidentified. Research performed where the initial aqueous phase only had $0.1 \mathrm{M} \mathrm{HNO}_{3}$ present showed, after extraction, an organic phase spectrum for $\mathrm{HNO}_{2}$ production similar to that observed in water without the large broad peak attributed to the additional species.

For the irradiation experiments where Np was present, a UV-vis spectra of the organic phase was taken prior to initiating the gamma radiolysis study to identify that there was no substantial change in oxidation state of the neptunium post extraction. Invariably there was a small amount of $\mathrm{Np}(\mathrm{V})$ found in the TBP phase, however these were not expected to have influenced the 
outcome of the experiment as at low dose (short irradiation times) the $\mathrm{Np}(\mathrm{V})$ present was seen to oxidize to $\mathrm{Np}(\mathrm{VI})$. At low acid concentrations the $\mathrm{Np}$ oxidation reaction was found to reverse when the samples had received $\sim 5.35 \mathrm{kGy}$ absorbed dose.

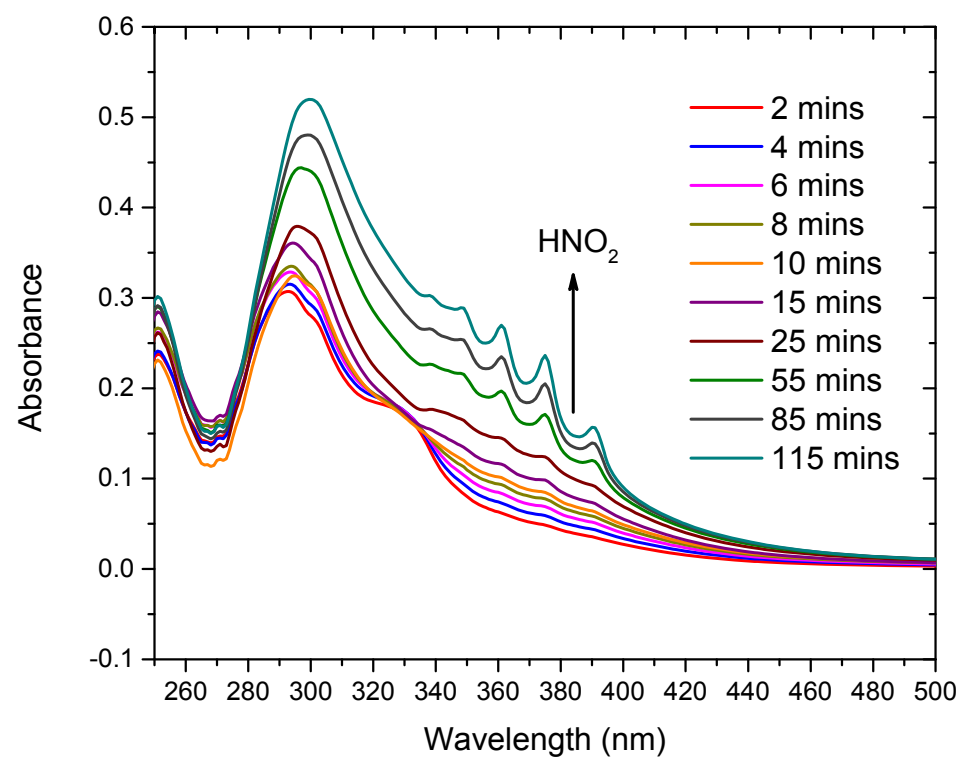

Figure 1. Differences in the absorbance spectra of extracted nitric acid as a function of time in the gamma irradiator. In this example the initial aqueous phase concentration of $\mathrm{HNO}_{3}$ was $1.0 \mathrm{M} \mathrm{HNO}_{3}$.

Above an absorbed dose of $5.35 \mathrm{kGy}$ there is enough $\mathrm{Np}(\mathrm{V})$ present in the organic phase that $\mathrm{Np}(\mathrm{V})$ cation-cation complexes (CCC's) begin to form. The absorbance peak at $1001 \mathrm{~nm}$ is indicative of this (Figure 2). ${ }^{3}$ However, with both $\mathrm{Np}(\mathrm{V})$ and $\mathrm{Np}(\mathrm{VI})$ ions present in these organic phase solutions it is not clear if these CCC's are $\mathrm{Np}(\mathrm{V})-\mathrm{Np}(\mathrm{V})$ complexes or $\mathrm{Np}(\mathrm{V})$ $\mathrm{Np}(\mathrm{VI})$ complexes. 


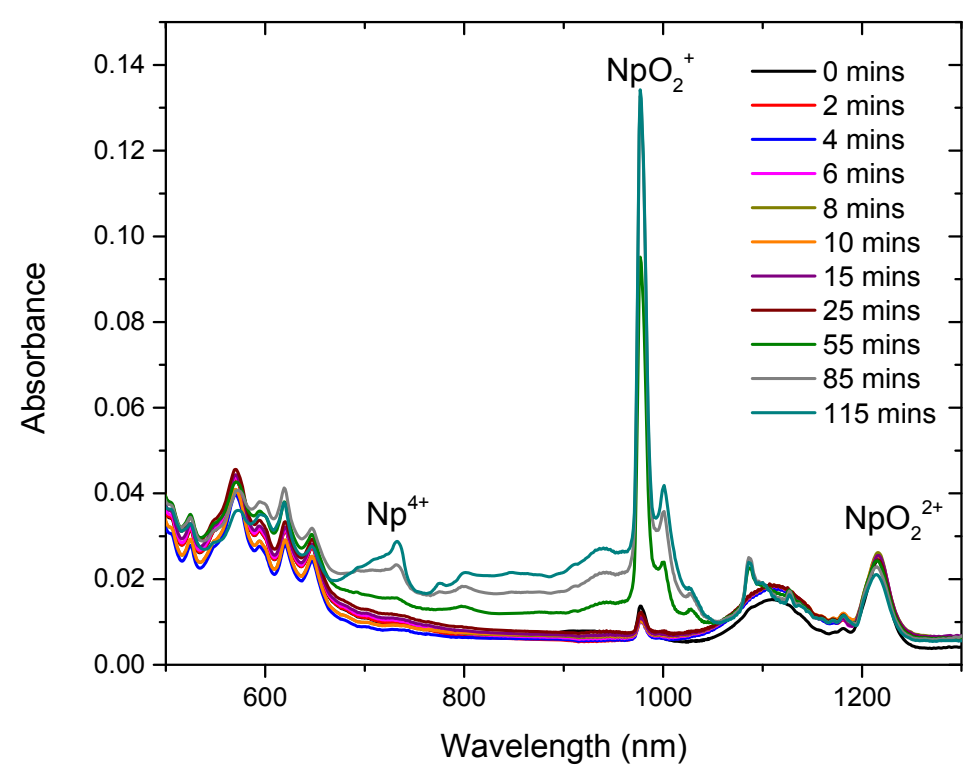

Figure 2. UV-vis spectra of changing organic phase $\mathrm{Np}$ speciation with absorbed dose. Extracted $\mathrm{Np} \sim 6$ $\mathrm{mM}$, initial aqueous phase acidity $1.0 \mathrm{M} \mathrm{HNO}_{3}$.

Figure 3 is indicative of the behavior observed at higher initial aqueous phase acidities (above $4.0 \mathrm{M})$ large quantities of $\mathrm{Np}(\mathrm{V})$ are only observed briefly, swiftly followed by an increase in $\mathrm{Np}(\mathrm{IV})$ in the organic phase. The presence of $\mathrm{Np}(\mathrm{IV})$ is taken to be evidence of disproportionation that is known to be significantly faster in TBP/kerosene organic phases. This is the most significant difference in behavior from the aqueous phase where no Np(IV) is observed with increasing dose. Disproportionation may also account for why there is only a small reduction in the $\mathrm{Np}(\mathrm{VI})$ concentration throughout the course of the experiment. However, further investigations are required to verify the disproportionation behavior.

All experiments were performed in the presence and absence of an aqueous phase. In the samples where an aqueous phase was present there was not found to be any appreciable $\mathrm{Np}(\mathrm{V})$ back extraction. This was an unexpected result as $\mathrm{Np}(\mathrm{V})$ is not usually stable in TBP solutions. It is envisaged that in the low volume $1 \mathrm{~cm}$ cuvette the surface tension between the organic and aqueous phases was high enough that it prevented adequate mixing between the two phases such that the $\mathrm{Np}(\mathrm{V})$ would back extract. 


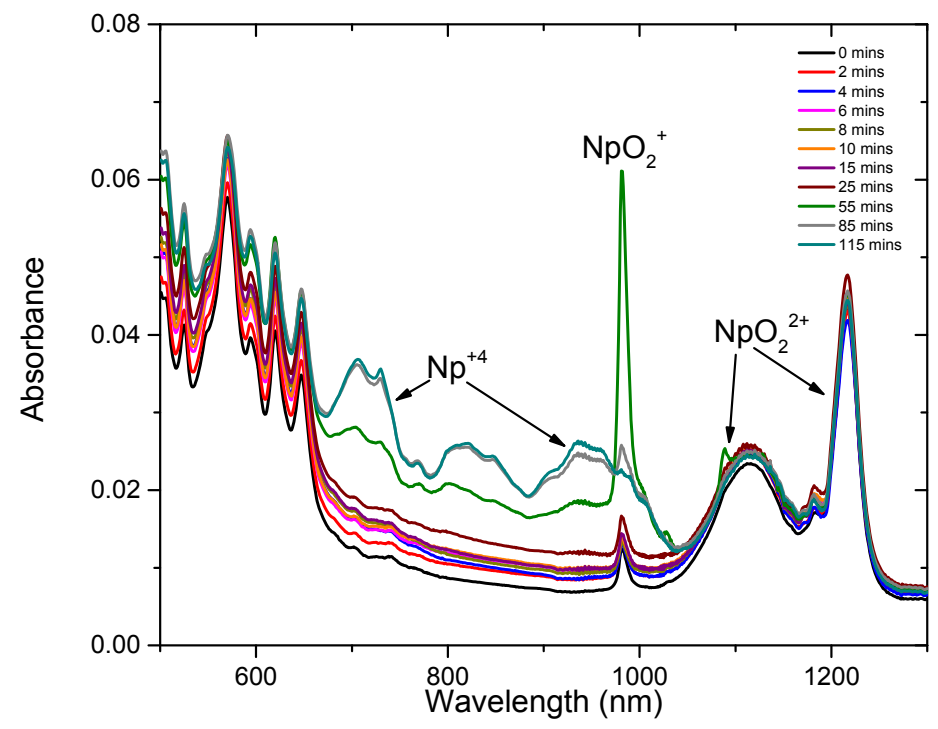

Figure 3. UV-vis spectra of changing organic phase Np speciation with absorbed dose. Initial organic phase $[\mathrm{Np}] \sim 6 \mathrm{mM}$, initial aqueous phase acidity $4.0 \mathrm{M} \mathrm{HNO}_{3}$.

\section{Conclusions}

Irradiated organic TBP solutions containing extracted $\mathrm{Np}(\mathrm{VI})$ were found to behave similarly to those in aqueous solution up to an absorbed dose of $5.35 \mathrm{kGy}$. Above this dose the chemistry appears to deviate from that of the aqueous phase example with significant production of $\mathrm{Np}(\mathrm{V})$. 2 The large amount of $\mathrm{Np}(\mathrm{V})$ produced leads to the formation of $\mathrm{Np}(\mathrm{V})$ cation-cation interactions being observed spectroscopically however, it is not clear if these are $\mathrm{Np}(\mathrm{V})-\mathrm{Np}(\mathrm{V})$ complexes or $\mathrm{Np}(\mathrm{V})-\mathrm{Np}(\mathrm{VI})$ complexes. There was found to be no observable differences in the samples that contained both the organic and aqueous phases to the organic only samples (no Np back extraction to the aqueous phase). However, this may be due to poor mixing between the two phases in the UV-vis cuvette. Unlike the prior aqueous phase work, evidence of $\mathrm{Np}(\mathrm{V})$ disproportionation is observed through the eventual presence of $\mathrm{Np}(\mathrm{IV}){ }^{2}$

\section{References}

1. M Precek, A. Paulenova, B.J. Mincher, Procedia Chemistry 7, 51-58 ( 2012 ).

2. B.J. Mincher, M Precek, S.P. Mezyk, G. Elias, L.R. Martin and Radiochimica Acta, 101, 259-265 (2013).

3. M. J. Sarsfield, R. J. Taylor and C. J. Maher, Radiochimica Acta, 95, 677-682 (2007). 


\section{Milesotne Participants}

1. Leigh R. Martin (PI)

2. Tamara Griffiths (visiting scientist)

3. Catherine Riddle 